\title{
Secondary Metabolites Contents and Antioxidant Capacities of Acmella Oleraceae Grown under Different Growing Systems
}

\author{
D.C. Abeysinghe ${ }^{1}$, S.M.N.K. Wijerathne ${ }^{1}$, R.M. Dharmadasa ${ }^{2, *}$ \\ ${ }^{1}$ Department of Plantation Management, Faculty of Agriculture and Plantation Management, Wayamba University of Sri Lanka, \\ Makandura, Gonawila (NWP) \\ ${ }^{2}$ Industrial Technology Institute, Bawddhaloka Mawatha, Colombo, Sri Lanka \\ *Corresponding author: dharmadasarm@gmail.com
}

Received July 04, 2014; Revised July 11, 2014; Accepted July 16, 2014

\begin{abstract}
Acmella oleraceae (L.) R.K. Jansen (Asteraceae) is a therapeutically important medicinal plant used in traditional systems of medicine. Present study was undertaken to compare the total phenolic contents (TPC), total flavonoid contents (TFC), total antioxidant capacity (TAC) and Thin Layer Chromatography (TLC) profiles of areal parts and callus extracts of A. oleraceae grown under different growing systems (field grown, hydroponically grown and callus culture. Callus established in Murasige and Skoog (MS) medium, areal parts of field grown and hydroponically grown plants were extracted in $80 \%$ methanol. TPC, TFC and TAC were carried out by using colorimetric Folin-Ciocalteu method, aluminum nitrate method and Ferric Reducing Antioxidant Power (FRAP) assay respectively. TLC profiles were developed using established protocol. The best callus growth and the highest mean callus weight were observed in leaf explants established in MS medium supplemented with $2 \mathrm{mg} / \mathrm{L} \mathrm{BA}$ and 1 mg/L IBA. Comparatively higher TPC (11.45 \pm 0.17$)$, TFC (12.33 \pm 0.92$)$ and TAC $(10.27 \pm 0.28)$ were observed in hydroponically grown plants. Order of TPC, TFC and TAC were increased as callus $<$ field grown plants $<$ hydroponically grown plants. The presence of higher TPC, TFC and TAC in hydroponically grown plants opens a new window for use of hydroponic system for growing of A. oleraceae for better secondary metabolites content.
\end{abstract}

Keywords: Acmella oleracea, antioxidant capacity, Asteraceae, flavonoids, phenolics

Cite This Article: D.C. Abeysinghe, S.M.N.K. Wijerathne, and R.M. Dharmadasa, "Secondary Metabolites Contents and Antioxidant Capacities of Acmella Oleraceae Grown under Different Growing Systems." World Journal of Agricultural Research, vol. 2, no. 4 (2014): 163-167. doi: 10.12691/wjar-2-4-5.

\section{Introduction}

Acmella oleraceae (L.) R.K. Jansen (Asteraceae) commonly known as "Toothache Plant" is an important medicinal plant occurring in the tropical and subtropical part of the world [1]. It is an annual or short-lived perennial herb, 20-60 cm tall, with a prostrate or ascending branched cylindrical stem. Leaves are simple ovate opposite without stipules. The flowers are yellow, non-fragrant with five petals on long glabrous peduncles [2]. This plant has been widely used in traditional and folk systems of medicine as an anti-inflammatory, anti-septic and anesthetic drug since historic times [3]. In traditional medicine, flowers have been chewed for toothache and the powdered leaves are rubbed on the lips and gums for soremouth in children [2].

The therapeutic value of a plant depends on chemically active substances which produce a specific physiological action on the human body. Bioactive compounds (i.e. phenolics and flavonoids) and antioxidant activity are most significant parameters which regulate the therapeutic effects of a plant [4]. However, comparatively more space and time are required to obtain secondary metabolites of medicinal plants under conventional agricultural methods. Therefore, alternative and effective growing systems to meet with enhanced commercial demand are necessary [5]. Moreover, alternative growing systems such as hydroponic culture, tissue culture are widely practiced for fruits, legumes, tomato, cucumber, and flower production [6]. Further, suitability of hydroponic culture, callus culture and tissue culture for secondary metabolite production of Plumbago indica have been investigated [7]. However, information on use of alternative growing systems for secondary metabolite production of $A$. oleraceae is very rare or lacking. Therefore, in the present study attempts were made to investigate the total phenolic contents (TPC), total flavonoid contents (TFC), total antioxidant capacity (TAC) and Thin Layer Chromatography (TLC) profiles of areal parts and callus extracts of $A$. oleraceae grown under different growing systems.

\section{Materials and Methods}

\subsection{Location}


Experiment was carried out during March to June 2014 at the laboratory of Herbal Technology Section of Industrial Technology Institute, Colombo 07, Sri Lanka and the laboratory of the Department of Plantation Management, Wayamba University of Sri Lanka, Makandura, Gonawila.

\subsection{Establishment of Mother Plants}

\section{Field Grown Plants}

Mother plants were obtained by sowing healthy vigorous seeds and seedlings were transferred to the plots containing medium (soil: compost 1:1). Watering was done daily.

\subsection{Hydroponically Grown Plants}

Non circulating hydroponic system was used to establish mother plants. Well rooted $A$. oleraceae plants were transferred into small cups containing brick pieces and establish in rigid-form boxes. $(0.45 \mathrm{~m} \times 0.375 \mathrm{~m} \times 0.2 \mathrm{~m})$ containing Albert's solution. Albert's solution was prepared by adding $1 \mathrm{~g}$ of Albert's mixture (CIC Company, Sri Lanka) to $1 \mathrm{~L}$ of water.

\subsection{Preparation of Culture Medium}

Murashige and Skoog (MS) medium supplemented with $3 \%$ sugar and $0.7 \%$ agar was prepared and $\mathrm{pH}$ was adjusted to 6.0 prior to autoclaving. The medium was autoclaved at $121^{\circ} \mathrm{C}$ and 15 psi of pressure for 20 minutes.

\subsection{Callus Induction from Leaf Explant}

The leaf explants were taken from hydroponically grown, healthy, five months old $A$. oleraceae plants. They were washed with running tap water for $1 \mathrm{~h}$ Subsequently explants were cleaned with $0.2 \%$ (v/v) aqueous “Teepol” to remove the dirt. Then it was treated with $1 \%(\mathrm{w} / \mathrm{v})$ systematic fungicide solution for $1 \mathrm{~h}$ Then, explants were washed with distilled water for five repeated times. After that, explants were dipped in different concentrations of $\mathrm{NaOCl}$ (5\%, 10\%, 15\% and 20\%) for $10 \mathrm{~min}$. Subsequently, explants were sterilized with each solution and washed with sterilized double distilled water for five repeated times. Then sterilized explants were cut into 1x1 $\mathrm{cm}$ pieces and inoculated on Murashige and Skoog (MS) supplemented with optimized concentration of $2 \mathrm{mg} / \mathrm{L}$ Benzyl Adenine (BA) and $1 \mathrm{mg} / \mathrm{L}$ Indole-3-Butyric Acid (IBA). Cultures were incubated at $24^{0} \mathrm{C}$ with continuous light. Data on callus weight and overall growth score were recorded after 6 weeks.

\subsection{Sample Preparation for Chemical Analysis}

Leaves of field grown plants, hydroponically grown plants and in vitro generated callus were cut into pieces and dried shade first at room temperature $\left(28 \pm 2^{\circ} \mathrm{C}\right)$ for three days and then using an oven for $2 \mathrm{~h}$ at $40^{\circ} \mathrm{C}$. Then dried samples were ground into powder using a grinder.

\subsection{Preparation of Extracts}

Pre-prepared samples $(0.1 \mathrm{~g})$ were accurately weighed into $15 \mathrm{~mL}$ centrifuge tube and added $5 \mathrm{~mL}$ of $80 \%$ methanol. The sample was vortexed for $15 \mathrm{~min}$. and placed in a water bath at $6^{\circ} \mathrm{C}$ for $40 \mathrm{~min}$. and vortex procedure was repeated in $10 \mathrm{~min}$. intervals. Then samples were centrifuged at $4000 \mathrm{rpm}$ for $5 \mathrm{~min}$. and supernatant was decanted into $15 \mathrm{~mL}$ centrifuge tube and the remaining was re-extracted with $5 \mathrm{~mL}$ of $80 \%$ methanol. Both supernatants were collected and stored at $-20{ }^{0} \mathrm{C}$ prior to analysis.

\subsection{Determination of Total Antioxidant Capacity}

Total antioxidant capacity was determined using Ferric Reducing Antioxidant Power (FRAP) assay as described in literature [8]. Pre-prepared methanolic extract $(100 \mu \mathrm{L})$ was mixed with $900 \mu \mathrm{L}$ of freshly prepared FRAP reagent of $\mathrm{pH} 3.6$ containing $2.5 \mathrm{~mL}$ of $10 \mathrm{mmol} / \mathrm{L}, 2,4,6$,Tripyridyl-s-Triazine (TPTZ) solution in $40 \mathrm{mmol} / \mathrm{L}, \mathrm{HCl}$ plus $2.5 \mathrm{~mL}$ of $20 \mathrm{mmol} / \mathrm{L} \mathrm{FeCl}_{3}$ and $25 \mathrm{~mL}$ of $300 \mathrm{~mol} / \mathrm{L}$ acetate buffer. Absorbance of the reaction was measured at $593 \mathrm{~nm}$ using the spectrophotometer (Shimadzu, UV Mini 1240, Japan) after incubating for 4 minutes. The trolox was used as the standard solution.

\subsection{Determination of Total Phenolic Content}

The total phenolic content (TPC) was determined using a modified Folin-Ciocaltue method [9]. Briefly, $4 \mathrm{~mL}$ of distilled water and $0.5 \mathrm{~mL}$ of plant extract were added into a test tube. Then $0.5 \mathrm{~N}$ Folin Ciocalteu reagents $(0.5 \mathrm{~mL})$ was added and allowed to react for $3 \mathrm{~min}$. One milliliter of saturated sodium carbonate solution was mixed and samples were incubated in a water bath for $2 \mathrm{~h}$ at $30^{\circ} \mathrm{C}$. The absorbance was measured at $760 \mathrm{~nm}$ using UV visible spectrophotometer (Shimadzu UV-160). Gallic acid was used as the standard and total phenolic content in one gram of dried plant material was calculated and expressed as milligram of Gallic Acid Equivalent (GAE).

\subsection{Determination of Total Flavonoid Content}

Total flavonoid content was determined by a colorimetric method described by prevous studies [10] with slight modifications. Briefly, $0.5 \mathrm{~mL}$ of the plant extract was diluted with $3.5 \mathrm{~mL}$ of distilled water. Then $0.3 \mathrm{~mL}$ of $5 \% \mathrm{NaNO}_{2}$ solution was added to the mixture. After 6 minutes, $0.3 \mathrm{~mL}$ of a $10 \% \mathrm{Al}\left(\mathrm{NO}_{3}\right)_{3} \cdot 6 \mathrm{H}_{2} \mathrm{O}$ solution was added, and the mixture was allowed to stand for another $6 \mathrm{~min}$. Two milliliter of $2 \mathrm{M} \mathrm{NaOH}$ was added, and the total was made up to $8 \mathrm{~mL}$ with distilled water. The solution was well mixed, and the absorbance was measured immediately at $510 \mathrm{~nm}$ using UV visible spectrophotometer (Shimadzu UV-160). Rutin was used as the standard and total flavonoid content in one gram of dried plant material was calculated and expressed as mg of Rutin Equivalent (RE).

\subsection{Thin Layer Chromatography (TLC)}

The thin layer chromatography (TLC) was performed according to the method described in WHO guidelines with some modifications. About $5 \mu \mathrm{L}$ of the extract was spotted on TLC plates (pre-coated silica gel 60A $20 \times 20$ $\mathrm{cm} ; 0.2 \mathrm{~mm}$ thickness) and optimum solvent system 
(Chloroform : Dichloromethane : Cyclohexane : Methanol $5: 4: 1: 0.5)$ was poured into the chamber to a depth of just less than $0.5 \mathrm{~cm}$. The spotted plates were dried using a drier and place the plates vertically in the chamber saturated with mobile phase. They were observed under UV $366 \mathrm{~nm}$ and after spraying with vanillin-sulfuric acid. Then $R_{f}$ (Retardation factor) values and colour of the bands were recorded.

\subsection{Statistical Analysis}

Data were analyzed using the General Linear Model (GLM) procedure of SAS statistical package. Mean separation was carried out by Duncan's Multiple Range Test (DMRT). Results are expressed as means \pm SEM with $95 \%$ confidential level.

\section{Results and Discussion}

\subsection{Optimization of Suitable Sterilization Method for Culture Establishment}

Results of the experiment carried out to determine the optimum sterilization procedure for leaf explant of $A$. oleraceae were shown in Figure 1. Fungal contamination was appeared as white clusters on the explant while bacterial contamination appeared as milky spots just after 5 days of culture establishment. However, contamination percentage was decreased with theincreasing concentrations of $\mathrm{NaOCl}$. Higher live percentage (40\%) was recorded in leaf explants treated with $10 \% \mathrm{NaOCl} 10$ minutes $\left(\mathrm{T}_{2}\right)$. It was observed that browning percentage was increased when increasing concentrations of $\mathrm{NaOCl}$.

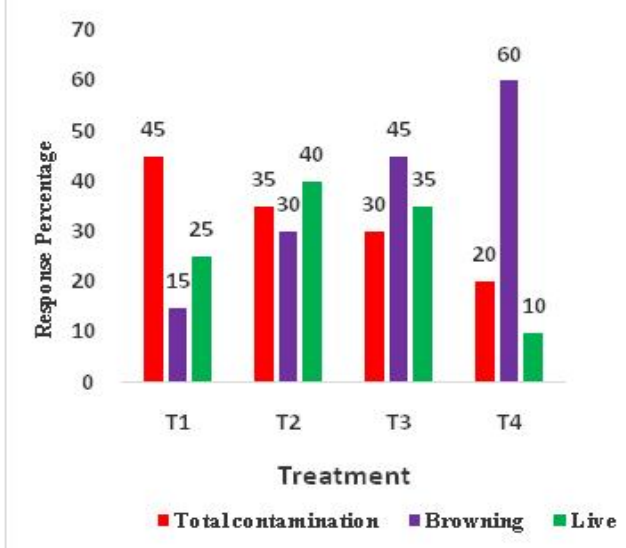

Figure 1. Contamination, browning and live percentages of leaf explants of A. oleraceae

$\mathrm{T}_{1}=5 \% \mathrm{NaOCl} 10$ min., $\mathrm{T}_{2}=10 \% \mathrm{NaOCl} 10$ min., $\mathrm{T}_{3}=15 \% \mathrm{NaOCl} 10$ min., $\mathrm{T}_{4}=20 \% \mathrm{NaOCl} 10 \mathrm{~min}$

In the present study, it is observed that leaf explants cultured in controlled treatment $(0 \mathrm{mg} / \mathrm{L}$ BA and $0 \mathrm{mg} / \mathrm{L}$ IBA) did not produce callus and remained as swollen explants. Moreover, there is a positive correlation with IBA concentration and callus growth. As shown in Table 1, significantly higher growth score and callus weight were exhibited in leaf explants cultured in MS medium supplemented with $2 \mathrm{mg} / \mathrm{L} \mathrm{BA}$ and $1 \mathrm{mg} / \mathrm{L}$ IBA and $\left(\mathrm{T}_{9}\right)$ and $1 \mathrm{mg} / \mathrm{L} \mathrm{BA}$ and $1 \mathrm{mg} / \mathrm{L}$ IBA $\left(\mathrm{T}_{6}\right)$. Out of these, the marked growth score $(9 \pm 0)$ and callus weight $(2.55 \pm 0.07)$ were exhibited in $\mathrm{T}_{9}$. Callus induction from leaf explants from Spilanthes acmella L., species have been achieved in MS medium supplemented with different auxin and cytokinin concentrations [1,11]. Therefore, the above evidences strengthen the results of the presence study.

Table 1. Growth score and mean weight of the callus produced in leaf cultures grown under different hormone combinations of BA and IBA

\begin{tabular}{|c|c|c|c|c|}
\hline \multicolumn{3}{|c|}{ Treatment } & \multirow{2}{*}{ Growth score } & \multirow{2}{*}{ Mean callus weight } \\
\hline & BA $(\mathbf{m g} / \mathrm{L})$ & IBA (mg/L) & & \\
\hline $\mathrm{T}_{1}$ & 0 & 0 & $3.0 \pm 0.0$ & $0.62 \pm 0.02^{\mathrm{a}}$ \\
\hline $\mathrm{T}_{2}$ & 0 & 0.5 & $5.0 \pm 0.0$ & $0.84 \pm 0.02^{\mathrm{ab}}$ \\
\hline $\mathrm{T}_{3}$ & 0 & 1 & $7.0 \pm 0.0$ & $0.93 \pm 0.01^{\mathrm{b}}$ \\
\hline $\mathrm{T}_{4}$ & 1 & 0 & $3.0 \pm 0.0$ & $0.62 \pm 0.01^{\mathrm{a}}$ \\
\hline $\mathrm{T}_{5}$ & 1 & 0.5 & $7.0 \pm 0.0$ & $0.93 \pm 0.19^{b}$ \\
\hline $\mathrm{T}_{6}$ & 1 & 1 & $9.0 \pm 0.0$ & $2.10 \pm 0.04^{\mathrm{c}}$ \\
\hline $\mathrm{T}_{7}$ & 2 & 0 & $3.0 \pm 0.0$ & $0.76 \pm 0.05^{\mathrm{bc}}$ \\
\hline $\mathrm{T}_{8}$ & 2 & 0.5 & $7.0 \pm 0.0$ & $1.70 \pm 0.09^{\mathrm{d}}$ \\
\hline $\mathrm{T}_{9}$ & 2 & 1 & $9.0 \pm 0.0$ & $2.55 \pm 0.07^{\mathrm{e}}$ \\
\hline
\end{tabular}

Mean values followed by the same latters are not significantly different at 0.05 confidence level

The secondary metabolites play an important role in therapeutic properties of plants. Moreover, chemical composition of secondary metabolites can also be varied with the nutrient composition of growing medium of the soil climatic conditions, seasonal variation, development stage of the plant [12]. In the present study, key secondary metabolites such as phenolics, flavonoids and antioxidant capacity of areal parts and callus extracts of A. oleraceae grown under different growing systems were assessed to ensure the suitability of growing system for secondary metabolite production. Further, TLC profiles of extracts taken from all growing systems were compared. As shown in Table 2, results demonstrated the presence of marked total phenolic content (TPC), total flavonoid content (TFC) and total antioxidant capacity (TAC) in extracts taken from all 3 different growing systems irrespective of growing system (Hydroponic system, field grown and callus culture). Significantly higher $(\mathrm{P}=0.05)$ secondary metabolite content and antioxidant capacity (TPC $=11.45$ $\pm 0.17, \mathrm{TFC}=12.33 \pm 0.92$ and $\mathrm{TAC}=10.27 \pm 0.28$ ) were observed in extracts taken from hydroponically grown plants followed by field grown plants and callus culture (Table 2). Order of TPC, TFC and TAC were increased as callus $<$ field grown plants $<$ hydroponically grown plants.

Table 2. Contents of total phenolics and total flavonoids and total antioxidant capacity of A. oleraceae

\begin{tabular}{cccc}
$\begin{array}{c}\text { Growing } \\
\text { System }\end{array}$ & $\begin{array}{c}\text { Total } \\
\text { Phenolic } \\
\text { Content (mg } \\
\text { GAE /g DW) }\end{array}$ & $\begin{array}{c}\text { Total } \\
\text { Flavonoid } \\
\text { Content (mg } \\
\text { RE /g DW) }\end{array}$ & $\begin{array}{c}\text { Total } \\
\text { Antioxidant } \\
\text { Capacity (mg TE } \\
\text { /g DW) }\end{array}$ \\
\hline Field & $10.99 \pm 0.25^{\mathrm{b}}$ & $11.33 \pm 0.73^{\mathrm{a}}$ & $9.23 \pm 0.17^{\mathrm{b}}$ \\
Hydroponic & $11.45 \pm 0.17^{\mathrm{a}}$ & $12.33 \pm 0.92^{\mathrm{a}}$ & $10.27 \pm 0.28^{\mathrm{a}}$ \\
Callus & $9.91 \pm 0.17^{\mathrm{c}}$ & $7.38 \pm 1.86^{\mathrm{b}}$ & $7.71 \pm 0.61^{\mathrm{c}}$
\end{tabular}

Mean followed by same later in each column are not significantly different at 0.05 level; GAE=gallic acid equivalent; $\mathrm{TE}=$ trolox equivalent; $\mathrm{RE}=$ rutin equivalent.

Presence of higher secondary metabolite contents and antioxidant capacity in hydroponically grown plants clearly indicate the suitability of hydroponically grown plants for commercial scale production of secondary metabolite of A. oleraceae. Moreover, presence of marked TPC, TFC and TAC in callus culture clearly indicates the 
possibility of using callus culture for secondary metabolite production from callus without scarifying plants. Therefore, the results of the present study will be highly useful for future drug development programmes. Antioxidant capacity, phenolic and flavonoid contents of field grown plants of $A$. oleraceae have also been investigated [9]. Moreover, genus specific secondary metabolites from callus culture of Artocarpus lakoocha.have been successfully investigated [12]. Further, in vitro method for the production of phenolic compounds from callus suspension cultures grown in MS medium supplemented with different combinations of auxin and cytokinin for Habenaria edgeworthii Hook. f. ex. Collett. have been studied [13]. Suitability of hydroponic growing system as an alternative method of secondary metabolite production of Datura innoxia Mill [14] and Plumbago indica has been investigated [7]. Therefore, the results of the present study are in agreement with previous studies carried out in elsewhere.

\subsection{Thin Layer chromatography (TLC)}

Thin layer chromatography (TLC) is the widely used analytical tool in herbal drug standardization process due to its simplicity and cost effectiveness [15]. As shown in Figure 2, TLC profiles observed under UV $366 \mathrm{~nm}$ exhibited the highest number of spots in extracts taken from field grown plants (10 spots) followed by hydroponically grown plants (8 spots) and callus culture (4 spots). A prominent, white color spot $\left(\mathrm{R}_{f} 0.49\right)$ was characteristic for callus extract while it was absent in field grown and hydroponically grown plant extracts. Four common spots $\left(\mathrm{R}_{f} 0.17, \mathrm{R}_{f} 0.36, \mathrm{R}_{f} 0.67, \mathrm{R}_{f} 0.86\right)$ for all samples were observed after spraying with vanillin sulfuric acid.

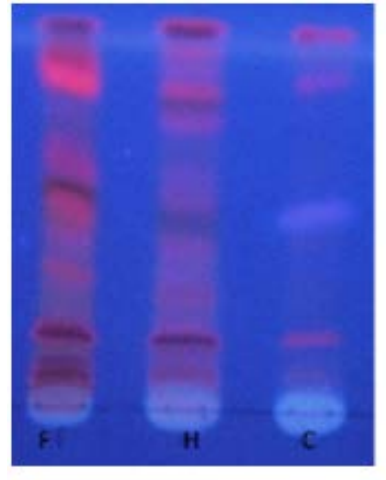

A

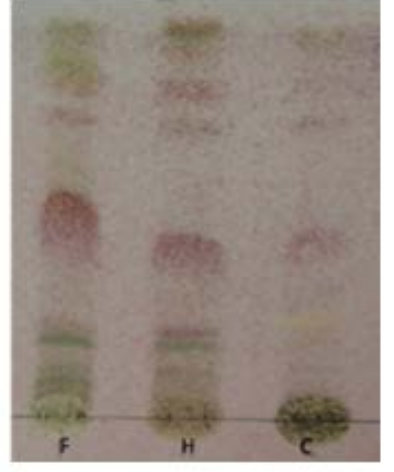

B
Figure 2. Thin Layer Chromatogram of A. oleraceae grown under different growing systems

A-under UV 366 nm; B- after spraying vanillin sulfuric acid; F-Field grown; H-Hydroponic grown; C-Callus

Applicability of TLC technique as a chemometric for quality evaluation of medicinal plants such as Acmella oleraceae [9], Gyrinops walla [16], (Plumbago indica grown under different growing systems [7], Munronia pinnata [17] have been successfully proven in previous studies.

\section{Conclusions}

Present study compared the phytochemical profile, total phenolic content, total flavonoid content and total antioxidant capacity of $A$. olearacea grown under different growing systems. Presence of higher contents of total phenolics, total flavonoids and total antioxidant capacity in hydroponic system scientifically proved the use of hydroponic system as an alternative method for the conventional field growing system to cater the existing raw material demand of $A$. oleracea. Further, results obtained through the thin layer chromatography, clearly confirmed the availability of secondary metabolites in plant materials taken from all 3 growing systems. Therefore, there is a strong possibility of extracting secondary metabolites from hydroponically grown plant and callus culture without scarifying plants in future programmes leading to drug development.

\section{Acknowledgments}

Authors wish to express their gratitude to all staff members of Herbal Technology Section of Industrial Technology Institute (ITI), Colombo 07 for their valuable assistance. We also would like to thank Mr. W.A.R. Wijesooriya, Technical Officer, Mr. H.M.A.S. Bandara and Mr. W.M.U.S. Bandara, lab attendants of Department of Plantation Management, Wayamba University of Sri Lanka for their great support.

\section{References}

[1] Pandey, V. and Agrawal, V. (2009).Efficient micro propagation protocol of Spilanthesacmella L. possessing strong antimalaria activity, In vitro cellular and development biology- plant, 45, 491499.

[2] Jayaweera, D.M.A., (1981). Medicinal Plants National Science Council of Sri Lanka, Colombo, Sri Lanka, 111, 71.

[3] Dias A.M.A., Santosa, P., Seabraa, I.J., Junior, R.N.C., Braga, M.E.M. and De Sousa, H.C (2011). Spilanthol from Spilanthes acmella flowers, leaves and stems obtained by selective super critical carbon dioxide extraction. The Journal of Supercritical fluids (in press).

[4] Chandur, U., Shashidhar, S., Chandrasekar, S.B., Bhanumathy, M. and Midhun, T. (2011). Phytochemical evaluation and antiarthritic activity of root of Saussure alappa. Pharmacologia, 2, 265-267.

[5] Gangopadhyay,M.,Dewanjee, S., Chakraborty D. and Bhattacharya, S. (2011). Role of exogenous phytohormones on growth and plumbagin accumulation in Plumbago indica hairy roots and conservation of elite root clones via synthetic seeds. Ind. Crops Prod, 33, 445-450.

[6] Morard, P. (1995). Les cultures végétales hors sol. Publications agricoles, Agen, France, ISBN: 2-9509297, 303.

[7] Lenora, R.D.K., Dharmadasa, R.M., Abeysinghe, D.C. and Arawwawala, L.D.A.M. (2012).Investigation of Plumbagin Content in Plumbagoindica Linn.Grown under Different Growing Systems.Pharmacologia, 3: 57-60.

[8] Abeysinghe, D.C., Li, X., Sun, C., Zhang, W., Zhou, C. and Chen, k., (2007). Bioactive compounds and antioxidant capacities in different edible tissues of citrus fruits of four species, Food Chemistry, 104, 1338-1344.

[9] Abeysiri, G.R.P.I., Dharmadasa, R.M. and Abeysinghe, D.C, and K. Samarasinghe (2013).Screening of phytochemical, physicochemical and bioactivity of different parts of Acmella oleraceae Murr. (Asteraceae), a natural remedy for toothache. Industrial Crops and Products, 50, 852-856.

[10] Benzie IFF and Strain JJ (1996) The ferric reducing ability of plasma as a measure of antioxidant power: The FRAP assay. Journal of analytical Biochemistry, 293: 70-76.

[11] Singh, M. and Chaturvedi, R. (2012). Screening and quantification of an antiseptic alkylamide, spilanthol from in vitro cell and tissue cultures of Spilanthes acmella Murr. Industrial Crops and Products, 321-328. 
[12] Menkovic, N., Savikin-Fodulovic, K. and Savin, K. (2000). Chemical composition and seasonal variations in the amount of secondary compounds in Gentianalutealeaves and flowers. Planta Med, 66, 178-180.

[13] Giri, L., Dhyani, P., Rawat, S., Indra, D., Shyamal, B., Nandi, K., Rawal, R.S. and Pande, V. (2012) In vitro production of phenolic compounds and antioxidant activity in callus suspension cultures of Habenariaedgeworthii: A rare Himalayan medicinal orchid. Industrial Crops and Products 39, 1-6.

[14] Gontier, E., Clement, A., Tran, T.L.M., Gravot, A., Lievre, K, Guckert, A. and Bourgaud, F. (2002). Hydroponic combined with natural or forced root permeabilization: A promising technique for plant secondary metabolite production. Plant Science, 163, 723732.
[15] Aman D. Kaur, V. Ravichandran, Prateek K.Jain, Ram K. Agrawal (2008). High-performance thin layer chromatography method for estimation of conessine in herbal extract and pharmaceutical dosage formulations. 46(2), 391-394.

[16] Dharmadasa, R.M., Samarasinghe K, Adhihetty,P. and Hettiarachchi P.L. (2013) Comparative Pharmacognostic Evaluation of Munronia pinnata (Wall.) Theob. (Meliaceae) and Its substitute Andrographis paniculata (Burm.f.) Wall. Ex Nees (Acanthaceae).

[17] Dharmadasa, R.M., Asitha Siriwardana, Kosala Samarasinghe, and Adhihetty, P. (2013). Standardization of Gyrinops Walla Gaertn. (Thymalaeaceae): Newly Discovered, Fragrant Industrial Potential, Endemic Plant from Sri Lanka. World Journal of Agricultural Research 1, No. 6: 101-103. 